\title{
The effects of chlorpromazine, trifluoperazine, and caffeine, administered orally, on performance of the albino rat measured by an operant conditioning and a cognitive task
}

\author{
TERRY L. HOLTZ \\ 508 Edgewater Drive, Kokomo, Indiana \\ and \\ MELVIN L. GOLDSTEIN \\ 508 Edgewater Drive, Kokomo, Indiana
}

\begin{abstract}
This experiment investigated the effects of chlorpromazine (Thorazine), trifluoperazine (Stelazine), and caffeine on acquisition of an operant conditioning task and on the learning of a cognitive T-maze task. Thirsty rats conditioned to press a lever for water in the Skinner box were given daily oral dosages of Thorazine $(3 \mathrm{mg} / \mathrm{kg})$, Stelazine $(10 \mathrm{mg} / \mathrm{kg})$, and caffeine $(25 \mathrm{mg} / \mathrm{kg})$. Subjects demonstrated a marked decrease in response rate after administration of Thorazine and Stelazine. Subjects on caffeine demonstrated a mild increase in response rate. Subjects run on a T-maze showed that Thorazine, Stelazine, and caffeine all decreased performance on the cognitive task. All experimental subjects showed approximately $60 \%$ weight loss.
\end{abstract}

Thorazine, in general, has been found to reduce the rate of responding in the Skinnerian barpress situation in which positive reinforcement is used (Iversen \& Iversen, 1975, p. 150; Sanger \& Blackman, 1975). This drug has also been shown to reduce performance in acquisition of shuttlebox conditioned avoidance responses (Ageel, Chin, Trafton, Jones, \& Picchioni, 1976). Similar information is not readily available for Stelazine and caffeine. The comparative effects of these drugs, as measured by an operant conditioning task, apparently have not been reported previously. In addition, the literature does not seem to include any comparisons of the effects of these drugs on the learning of a simple operant conditioning task and on the learning of a more complex cognitive task.

The purpose of the present experiment was, therefore, to determine the effects of chlorpromazine (Thorazine), trifluoperazine (Stelazine), and caffeine on acquisition of an operant conditioning task and on the learning of a cognitive T-maze task.

Data collection for the experiment was begun in September 1977 and was completed in April 1978. The paper was written (for publication) in August 1983. Terry L. Holtz gratefully acknowledges the assistance of Robert J. Weidman, Jr., in the data collection. Charles C. Couch made the drawings. Andy Elledge typed the manuscript. Melvin L. Goldstein is affiliated with the Department of Psychology, Indiana University, Kokomo, Indiana 46902. Requests for reprints should be sent to Terry $L$. Holtz, 508 Edgewater Drive, Kokomo, Indiana 46902.

\section{METHOD}

\section{Subjects}

The subjects used in the present experiment were eight naive male albino rats obtained from the Holtzman Company, Madison, Wisconsin. They were approximately 90 days old when Skinner box conditioning began. Their weights ranged from 340 to $420 \mathrm{~g}$. They were housed in individual cages during the experiment and were maintained, ad lib, on Purina Rat Chow.

Four groups, each consisting of two subjects, were used in the experiment. Group I was given Thorazine; Group II was given Stelazine; Group III was given caffeine. Group IV was the control group. This group was maintained on the same $23.5-\mathrm{h}$ water-deprivation schedule as the other groups.

\section{Apparatus}

The apparatus used in the experiment was a hand-operated Skinner box manufactured by Scientific Prototype Corporation.

The T-maze used in the experiment was made from corrugated cardboard. The main alley measured $.6 \mathrm{~m}$ long, and the legs of the $T$ each measured $29.2 \mathrm{~cm}$ long. Water was the reinforcement and was placed in the left leg of the T-maze, which was used as the "goal" box throughout this portion of the experiment.

\section{Procedure}

The experimental design consisted of three sessions. The first session was an operant conditioning session. The second session was an operant conditioning test session. The third session was a cognitive test session in which the T-maze was used.

Session I: Initial Skinner box conditioning. The subjects were conditioned in the Skinner box prior to the start of the drug schedule, in order to obtain a baseline operant response measure for each group. This session lasted 60 consecu tive days.

Session II: Operant conditioning test. Group I was given Thorazine orally, ad lib, in daily dosages of $3 \mathrm{mg} / \mathrm{kg}$ of body weight. Group II was given Stelazine orally, ad lib, in daily 
dosages of $10 \mathrm{mg} / \mathrm{kg}$ of body weight. Group III was given caffeine orally, ad lib, in daily dosages of $25 \mathrm{mg} / \mathrm{kg}$ of body weight. Group IV was not given any of these drugs and was used as a control group; it was maintained on the same 23.5 -h waterdeprivation schedule as the three groups given drugs. This session lasted 61 days, during which time each subject was run in the Skinner box three times per week. Each subject was weighed weekly in order to determine weight changes resulting from the drug treatment.

Session III: Cognitive task situation (T-maze). The three drugged groups from Session II of this experiment and the control group were placed in the T-maze. The time it took each subject to complete the maze was recorded. Session III lasted for 31 consecutive days.

\section{RESULTS}

The results of the operant conditioning portion of the experiment showed that Thorazine and Stelazine both caused a decrease in the rate of operant behavior. Caffeine had relatively little effect on this task. These results are shown in Figure 1.

The results of the cognitive task indicated that there was some correspondence between administration of Thorazine and Stelazine and the subjects' ability to learn the T-maze. The subjects given these two drugs could not learn the $\mathrm{T}$-maze, even after repeated exposure to the situation. These results are shown in Figure 2.

All three drugs caused a weight loss in the subjects. The subjects in Group I (Thorazine) decreased to a mean of $57 \%$ of initial body weight. The subjects in Group II (Stelazine) decreased to a mean of $60 \%$ of initial body weight. The subjects in Group III (caffeine) decreased to a mean of $65 \%$ of initial body weight. The subjects in Group IV (Control) decreased to a mean of $87 \%$ of initial body weight.

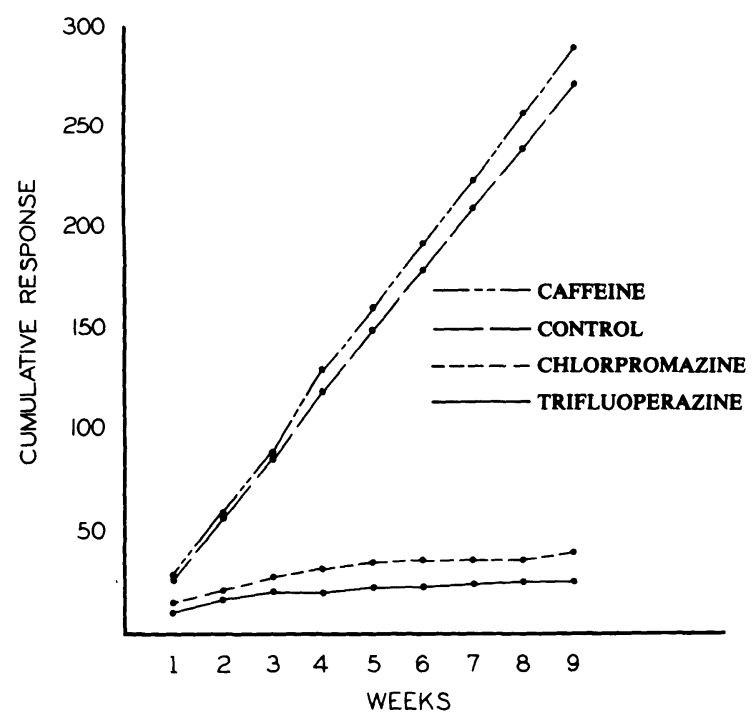

Figure 1. Weekly cumulative response curves for the drugged and the control rats.

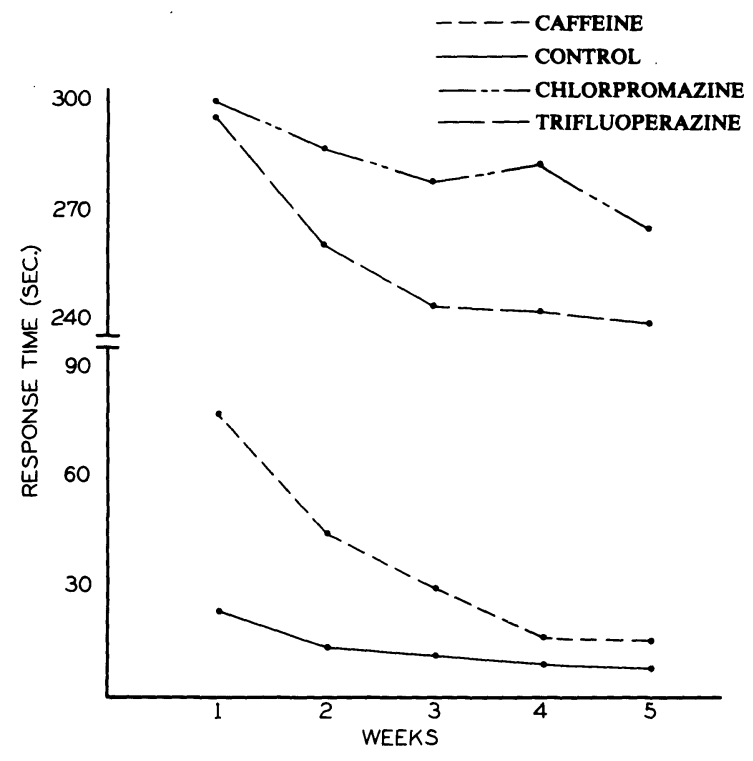

Figure 2. Weekly response times for rats run in the T-maze.

The subjects given Thorazine and Stelazine were, in general, nonresponsive and lethargic throughout the experiment. The subjects given caffeine were, in general, responsive and active throughout the experiment.

\section{DISCUSSION}

Thorazine and Stelazine, administered to subjects in an operant conditioning situation, slowed motor performance rate, whereas caffeine had relatively little effect.

The two drugs used in this experiment disrupted the ability of the experimental subjects to learn the T-maze. The control group learned the T-maze rather quickly. The subjects given Thorazine and Stelazine could not learn the T-maze, whereas the subjects given caffeine did learn the T-maze.

Under the conditions of the present experiment, Thorazine and Stelazine had a slowing effect on motor performance, as measured by the Skinner box, and also interfered with cognitive learning, as measured by the T-maze.

The results of the experiment suggest that, in the future, research should be directed toward answering the following question: Is the cognitive learning deficit obtained after administration of these drugs a permanent one, or is it a temporary, statedependent learning deficit that would be eliminated after subjects have been freed of the drugs?

\section{REFERENCES}

Ageel, A. M., Chin, L., Trafton, C. L., Jones, B. C., \& Picchioni, A. L. (1976). Acute effects of morphine and chlorpromazine on the acquisition of shuttle box conditioned avoidance response. Psychopharmacologia, 46, 311-315.

IVERSEN, S. D., \& IverSEN, L. L. (1975). Behavioral pharmacology. New York: Oxford University Press.

Sanger, D. J., \& Blackman, D. E. (1975). The effects of tranquilizing drugs on timing behavior in rats. Psychopharmacologia, 44, 153-156.

(Manuscript received for publication December 23, 1983.) 